This is an open-access article distributed under the terms of the Creative Commons Attribution License, which permits unrestricted use, distribution, and reproduction in any medium, provided the original author(s) and source are credited.

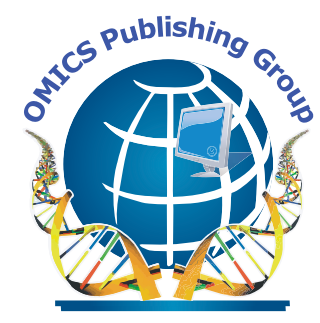

ISSN: 2165-7386

\title{
Journal of Palliative Care \& Medicine
}

The International Open Access

Journal of Palliative Care \& Medicine

Executive Editors

David M Steinhorn

Northwestern University, USA

Scott A Murray

University of Edinburgh, UK

Peter C Coyte

University of Toronto, Canada

Margaret O'Connor

Monash University, Australia

\section{Anne Wilkinson}

Edith Cowan University, Western Australia

Available online at: OMICS Publishing Group (www.omicsonline.org)

This article was originally published in a journal by OMICS

1 Publishing Group, and the attached copy is provided by OMICS Publishing Group for the author's benefit and for the benefit of the author's institution, for commercial/research/educational use including without limitation use in instruction at your institution, sending it to specific colleagues that you know, and providing a copy to your institution's administrator.

All other uses, reproduction and distribution, including without limitation commercial reprints, selling or licensing copies or access, or posting on open internet sites, your personal or institution's website or repository, are requested to cite properly. 


\title{
Exploring the Challenges of Implementing the Edmonton Symptom Assessment Scale in a Specialist Palliative Care Unit
}

\section{Lucey ${ }^{1 *}$, M Conroy ${ }^{2}$ and K Ryan ${ }^{3}$}

${ }^{1}$ Consultant in Palliative Medicine in Milford Hospice, Limerick, Ireland ${ }^{2}$ Consultant in Palliative Medicine in Milford Hospice, Limerick, Ireland ${ }^{3}$ Consultant in Palliative Medicine, St Francis Hospice, Raheny, Ireland

\begin{abstract}
Background: Many symptom assessment tools have been developed to aid evaluation of patient's symptoms. The Edmonton Symptom Assessment Scale is one such tool. The ESAS was introduced on the inpatient unit in Milford Hospice (a 30 bedded tertiary palliative care unit) in December 2007. However, a 3-month chart review revealed a low completion rate $(20 \%)$ of the ESAS.

Aim: The aim of this study was to assess the reasons for the low completion rate of the ESAS in the unit. Methods: A mixed methods approach using both questionnaire and focus group was undertaken. The population sampled was the nursing staff who were responsible for ensuring the completion of the ESAS in the unit on a daily basis.

Results: The main reason for the low completion rate of the ESAS was that nursing staff perceived that it was too burdensome for sick patients to complete $(76 \%)$. Also, nursing staff felt that the tool was not clinically helpful and that it was too time consuming for patients to regularly complete. Other important issues relating to the introduction process for symptom assessment tools are also identified.

Conclusions: The results of this study are consistent with findings in the literature relating to other symptom assessment tools. Implementing such tools may be burdensome for patients with a poor functional status in an advanced cancer setting. Areas of focus for further research include shorter symptom assessment tools which are more reflective of a patients twenty four hour symptom profile, and also proxy rated assessment tools.
\end{abstract}

Keywords: Edmonton symptom assessment scale; Palliative care unit; Nursing perceptions; Patient burden

\section{Introduction}

Many patients admitted to specialist palliative care units have troublesome and challenging symptoms. In patients with advancing cancer, symptom burden worsens with cancer stage [1] and this symptom distress decreases quality of life [2]. Many symptom assessment tools have been developed to assist with symptom evaluation and measurement. In one study looking at the number of symptom assessment tools available, 21 symptom assessment tools were identified with another 28 in existence examining symptom prevalence and interrelations [3]. One such symptom assessment tool, the Edmonton symptom assessment scale or ESAS, has received much attention in recent times. Developed by Bruera et al in 1991 it is an 11 point numerical rating scale used to rate 9 symptoms with an optional $10^{\text {th }}$ symptom nominated by the patient. The presence and severity of each symptom is scored from 0 to 10 . The scoring process can be completed by the patient alone or with the help of a caregiver. If the patient is unable to complete the exercise the care-giver can do so on their behalf $[4,5]$.

In December 2007 the ESAS was introduced as a quality indicator of symptom control in the specialist palliative care unit of Milford Hospice.This is a thirty-bedded specialist palliative care unit in Limerick, Ireland, where most patients admitted have advanced cancer $(>90 \%)$ and where $10 \%$ have non-malignant disease (Table 1 ). The introduction of the ESAS was reflective of a more general quality assurance drive within the hospice which was part of an organisational accreditation process.

\section{Introduction of the ESAS}

Staff were educated in the use of the ESAS. The researcher held 2 educational sessions each for nursing staff, management and non- consultant hospital doctors. A further 2 sessions were held for the multidisciplinary team (a total of eight sessions). It was explained that the 11 point horizontal numerical scale ESAS was to be completed by the patient with the admitting doctor on admission and thereafter by nursing staff once daily.

\section{Assessment of nursing perceptions of the ESAS}

After a three-month period, a chart review (40 charts) was undertaken with a view to assessing the completion rate of the ESAS. This revealed only a $20 \%$ successful completion of the ESAS on the wards. To investigate the cause of this low completion rate, a study was undertaken to assess nursing staff perceptions of the ESAS.

\section{Methods}

\section{Ethical approval}

Ethical approval for this study was obtained from the Midwestern Regional Hospital Ethics Committee in Limerick, Ireland. A mixed methods approach was undertaken using both a questionnaire and a focus group to assess the nursing staff perceptions of the ESAS. The sample was drawn from nursing staff who were working in the hospice during the introduction of the ESAS.

*Corresponding author: Dr. Michael Lucey, Consultant in Palliative Medicine Milford Hospice, Castletroy, Limerick, Ireland, Tel: +353868582026; E-mail: lucey_mike@hotmail.com

Received June 27, 2012; Accepted August 23, 2012; Published August 25, 2012

Citation: Lucey M, Conroy M, Ryan K (2012) Exploring the Challenges of Implementing the Edmonton Symptom Assessment Scale in a Specialist Palliative Care Unit. J Palliative Care Med 2:128. doi:10.4172/2165-7386.1000128

Copyright: $\odot 2012$ Lucey M, et al. This is an open-access article distributed under the terms of the Creative Commons Attribution License, which permits unrestricted use, distribution, and reproduction in any medium, provided the original author and source are credited. 


\begin{tabular}{|l|c|}
\hline Number of admissions & 83 \\
\hline Number of readmissions & 46 \\
\hline Total number of admissions & 129 \\
\hline Average length of stay & 12 days \\
\hline Patient outcomes & $54 \%$ discharged/ $46 \%$ Deaths \\
\hline Types of disease & $\begin{array}{c}\text { Breast/ lung/ Colonic / Prostate cancer }(>90 \%) \\
\text { Non malignant Disease }(<10 \%)\end{array}$ \\
\hline
\end{tabular}

Table 1: Statistics for 3-month period for Milford Hospice PCU.

\section{Survey}

A questionnaire was sent to all nursing staff $(n=20)$ in the unit by the internal mail system. This questionnaire was sent one month after the chart review had highlighted the low completion rate of the ESAS. It was clearly printed at the top of the questionnaire that it was confidential. Questionnaires were not signed and were returned to a box on the unit in unmarked envelopes.

\section{Focus group}

A focus group was held for nursing staff to discuss their views and perceptions of the ESAS $(n=8)$. This focus group was held one week after the questionnaires were distributed. Participation was voluntary and its occurrence and timing conveyed through posters placed on both wards in the unit. Eight $(n=8)$ nurses attended the focus group. The focus group was facilitated by the principle investigator (this author). This session was taped. Transcription was subsequently performed from the audio recording by a non-clinical third party in order that voices would not be identified or linked with what was said.

\section{Data Analysis}

\section{Questionnaire}

Data from questionnaires was collected and collated. Many respondents identified more than one cause for the low implementation rate of the ESAS. As such, the results of the survey represent the total number of positive responses for each question expressed as a percentage of the completed questionnaires (Table 2).

\section{Focus group}

Data was analyzed using a qualitative content analysis framework [6]. A categorical system [7] was employed to categorize information under a heading system to account for all interview data (excluding 'fillers' or 'dross') [8]. These multiple categories were then 'collapsed' into more useable higher order categories to better reflect general themes of the focus group. This categorization was then reviewed independently by two other professionals (Consultant and Head of Research) and independent categorizations were advised. The final categorizations were the most appropriate overall categorizations taken from the three separate reviews [8].

\section{Results}

\section{Questionnaire survey: (Table 2)}

There was an $85 \%(17 / 20)$ response rate to the questionnaire.

\section{Patient burden}

Thirteen respondents (76.5\%) felt that the ESAS was too difficult for sick patients to complete. Six respondents (35\%) felt that the ESAS was too time consuming for both patients and staff.

\section{Implementation process and education}

There were difficulties in relation to the introduction process of the ESAS on the ward. Eight respondents (47.1\%) felt that there was insufficient education at the time of introduction of the ESAS. Eight respondents (47.1\%) also felt there were more pressing organizational commitments during the introduction of the ESAS, and that these detracted from its implementation. Of note, Milford Hospice was undergoing a process of external accreditation as a part of continuous organizational and systems improvement in early months of 2008 .

\section{Perception of the ESAS}

Six respondents (35\%) didn't feel the ESAS was clinically significant or helpful. Five (29\%) felt that with their other daily commitments, they had forgotten to fill in the ESAS, whereas two (12\%) felt that they had not been reminded to complete the ESAS. One respondent $(6 \%)$ felt that the ESAS was a research project that didn't apply to daily ward duties.

\section{Reintroduction of the ESAS / modified assessment tool}

Most nurses (82\%) felt that there should not be any future attempt to reintroduce the ESAS on the unit. Only one respondent felt that it should be reintroduced.

On the question of what might make a symptom assessment tool more likely to be successfully implemented in the future, 12 respondents $(71 \%)$ felt that a shorter scale should be introduced, and $6(35 \%)$ felt that nurses should be consulted about the scale prior to its introduction. 4 (24\%) felt that if they were more involved in the design of a scale, that they would be more likely to use it. $6(35 \%)$ felt that there should be more emphasis on reminding staff at ward level to complete the ESAS. A summary of the questionnaire findings are given in table 2 and figure 1.

\section{Focus Group}

The findings of the focus group supported those of the survey.

Higher order (Key themes) of the data collected from the focus group revealed five major headings regarding the implementation at ward level of the ESAS:

1. Awareness

2. Interpretation.

3. Burden vs. benefit.

4. Leadership

5. Presentation

Awareness: Nurses were aware of the tools existence, however

\begin{tabular}{|l|c|c|}
\hline Barriers for low Implementation & $\begin{array}{c}\text { Respondent } \\
\text { numbers }\end{array}$ & Percentages \\
\hline ESAS was too difficult for patients to complete & $\mathrm{N}=13$ & $76.47 \%$ \\
\hline $\begin{array}{l}\text { Other more pressing organizational commitments } \\
\text { at the time. }\end{array}$ & $\mathrm{N}=8$ & $47.05 \%$ \\
\hline Insufficient education & $\mathrm{N}=8$ & $47.05 \%$ \\
\hline Thought ESAS was not clinically helpful & $\mathrm{N}=6$ & $35.29 \%$ \\
\hline ESAS was too time consuming to complete & $\mathrm{N}=6$ & $35.29 \%$ \\
\hline Forgot to complete the ESAS & $\mathrm{N}=5$ & $29.41 \%$ \\
\hline ESAS was only a research project and didn't & $\mathrm{N}=1$ & $5.88 \%$ \\
\hline apply to daily ward duties & $\mathrm{N}=1$ & $5.88 \%$ \\
\hline Thought the ESAS was over after a few weeks & $\mathrm{N}=3$ & $11.76 \%$ \\
\hline Were not reminded to fill out the ESAS & $\mathrm{N}=0$ & $0 \%$ \\
\hline Thought the ESAS was not important to complete & & \\
\hline
\end{tabular}

Table 2: Results of nursing questionnaire. Many respondents identified more than one cause for the low implementation rate of the ESAS. 


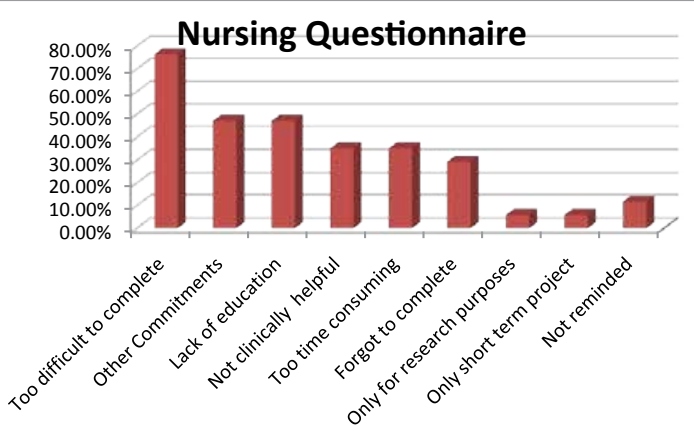

Figure 1: Nursing questionnaire.

\begin{tabular}{|c|c|}
\hline Awareness & $\begin{array}{l}\text { - } \quad \text { Lack of sufficient education. } \\
\text { - } \quad \text { Poor understanding of aim of tool. }\end{array}$ \\
\hline Interpretation & $\begin{array}{ll}\text { - } & \text { Language used. } \\
\text { - } & \text { Rating scales }(0-10) \\
\text { - } & \text { Symptom snapshot view vs. 24-hour symptom } \\
& \text { profile. } \\
\text { - } & \text { Graphing difficulties. }\end{array}$ \\
\hline Leadership & $\begin{array}{l}\text { Doctors / Nursing supervisors to drive } \\
\text { accountability for tool. } \\
\text { - } \quad \text { Refer to tool on ward rounds. } \\
\text { - Ensure clinical commitment to tool. }\end{array}$ \\
\hline Burden vs. Benefit: & $\begin{array}{l}\text { - } \quad \text { Best time for ward staff. } \\
\text { - } \quad \text { Not felt to help patient care } \\
\text { - } \quad \text { Inape consuming tool. } \\
\text { - } \quad \text { Patients unaware of benefit of tool. }\end{array}$ \\
\hline Presentation & $\begin{array}{l}\text { - Tool not appropriate in original format. } \\
\text { - Twenty-four hour retrospective tool more } \\
\text { representative of true symptom profile. } \\
\text { - Shorter, simpler tool with less number of } \\
\text { symptoms more appropriate. }\end{array}$ \\
\hline
\end{tabular}

Table 3: Key themes of focus group.

some felt it was not relevant to daily ward duties and that some doctors did not refer to it regularly.

'The other doctors didn't take any notice of it and it wasn't as though they were as enthusiastic about it as you were! (P2: 201-205)

Interpretation: Nurses felt that patients found the ESAS difficult to interpret and score and that some of the language/ concepts used were inappropriate for a very sick patient to understand. This was particularly true of some of the more subjective symptoms such as 'sense of wellbeing', 'Anxiety' or 'Depression'

- 'Ifelt the language was not appropriate for patients who were not very well.(P2: 36)

- 'The patients find it hard enough to give you a number for pain let alone give you a number for all of these questions.(P2:182183) The simpler you can keep a questionnaire the better. Maybe one or two points only.'(P3: 186-187)

Some nurses felt that sick patients found the ' $0-10$ ' scoring of the scale difficult.

'They could not figure out the numbers. You know, do I (the patient) go high or low?'(P4:141)

Nurses felt that the ESAS was misrepresentative of a patient's 24 hour symptom profile and that many patients only filled out the scale when they felt well enough to do so: 'So I could never understand the concept that two hours ago he was in agony but then we have given him a pain killer. So he is fine now, no pain. He writes down that he is ok. It only gives a snapshot. It wouldn't be a true reflection P2: 243-24, P3:248)'.

Leadership: Nurses felt that the doctors did not refer to the ESAS regularly on ward rounds, and in some cases did not fill out the initial ESAS on admission themselves: 'Well, I kind of felt nobody's asking for it, nobody's checking them on a daily basis. The consultants aren't asking about them. Sure what are we doing this for? (P2:195-198)

Obviously, any patient symptoms are addressed immediately by the medical staff in the unit, however, from a leadership perspective, doctors not referring to the ESAS routinely in the presence of the nursing staff added to the perception that they were not clinically useful.

Burden vs. benefit: It was expressed that staff felt that the ESAS was a burden to sick patients: 'It was very off-putting for the patient, that includes it was time consuming for the patient because... they were finding it so hard to find the answers. (P6:68-69) They would look at you and say 'ah, not that again'. (P6:75-76)

Presentation: Presentation refers to how the tool itself is presented to the patient. In this case, the tool is a sheet of paper with numerical rating scales. Nurses expressed the view that they felt that the ESAS as a tool was inappropriate for their patients: 'I suppose the biggest issue would have been the patients, when they saw you coming with that sheet. It was too much for them'.(P5: 227-228) 'For someone who is lying flat on the bed all day and just sick and nauseated....it's the last thing they want to do. (P2:235-238).

One suggestion made was that in place of a patient filled out, or a nurse assisted ESAS, a nurse filled out (proxy) 24-hour assessment of patient's symptoms would be better and more implementable. This could be performed with the omission of 'subjective symptoms' such as anxiety or sense of wellbeing.

The key themes of the focus group are summarized in table 3 .

\section{Discussion}

After introducing the ESAS in Milford Hospice, analysis of the completion rate of the tool after 3 months confirmed that it was not being regularly completed with only $20 \%$ being performed correctly on a daily basis. The causes of this low implementation rate became our focus of this research.

Both questionnaire and focus group data revealed consistent results. Many nurses felt that the ESAS was too difficult for sick patients to complete, and that it represented a burden for both patient and staff that did not necessarily provide accurate information as to patient's daily symptom profiles. These difficulties have been previously highlighted the wider literature. In one study, Rees et al. [9] evaluated the use of the ESAS in a palliative care unit in the UK. This study found that the ESAS was difficult and time consuming to complete and did not contribute data in addition to that obtained in normal clinical interaction. It also reported that they found that the tool was not practical for use in patients with a poor performance status. In another study Watanabe et al. [10] evaluated palliative care nurses perceptions of the ESAS's feasibility and usefulness in Alberta, Canada. This study, carried out in the Edmonton palliative care program, reported that most specialist palliative care nurses found the ESAS of benefit to both patients and staff. However it also highlighted that only $23 \%$ of Licensed Practical Nurses (LPNs) working within the hospice environment agreed with the statement that the ESAS 'did not take a lot of time and effort for patients to complete'. Our study focuses further on the evaluation of nursing perceptions of the ESAS as a daily 
tool for assessing patient's complex symptoms, and builds on the above evidence base. Analyzing the results of our study in light of the findings of both Rees' and Watanabe's studies we can see congruent results. All three studies highlight the perception that the ESAS may become difficult to implement in end of life situations, and may be of limited clinical assistance. This perception is also reflected in the broader symptom assessment literature. Chow et al. [11] and Labori et al. [12] suggest that only in certain contexts, such as with symptom palliation in hospitals, is daily ESAS administration reasonable. However even in this context there is concern regarding the benefits of fine tracking symptoms when these patients are deteriorating near the end of life.

In our study nurses expressed concern about the accuracy of the ESAS when using it on a daily basis. Many felt that patients were only giving a score for their symptoms a particular point in time. This obviously would be unreflective of the patient's 24 -hour symptom profile. Noticeable modifications to the ESAS exist throughout the literature in relation to the time period over which symptoms are scored. This period varies from as short as 'at present' or within the past few hours up to several days $[13,14]$ or even weeks $[15,16]$. This seems to be an area that needs to be further clarified in relation to the ESAS.

Most nurses felt that the ESAS should not be reintroduced (82\%), but that a shorter symptom scale, filled out by nursing staff ("proxy rating') could be introduced. However, many studies show that proxy ratings of patient's symptoms are not a consistently accurate reflection of patient distress. Nekolaichuk et al. [17] demonstrated that whereas nursing staff can often assign symptom scores that are similar to patient scores, Physicians often assign scores that are lower than patients own ratings for their symptoms [18]. In another study, Pautex et al. [19] reported that Physician and Nurse Assessments of patient symptom scores were similar; however both differed from patient ratings. Furthermore, this study found that the Physicians and Nurses underestimated physical symptoms and overestimated wellbeing, anxiety and depression. As such, further studies need to be undertaken to ascertain the appropriateness of proxy ratings relating to the implementation of the ESAS and other symptom assessment tools.

Concerns about the burden of completing symptom assessment tools are not new. Literature has shown that many of the present multidimensional tools are burdensome to use for both clinicians and patients especially for populations with advanced disease [20-25]. For example the SF-MPQ was regarded as too demanding to use by the EAPC expert working group and others [20,22]. A study using the full version of the BPI and the BPI-sf showed that fewer than $58 \%$ of patients were able to complete the full version, returning only partially completed questionnaires [24].The study concluded that the BPI was too burdensome for both patients and administrators. A similar finding was found in 2 other studies using the shortened version of the BPI [25].

As such, the available literature has highlighted some concerns about the symptom time-period being assessed by the ESAS, the necessity for further research into proxy rating methods for symptom assessment, and also concerns about the burden of ESAS and other symptom assessment tools on patients near the end of life. Our study concurs with this literature, and further highlights nursing concerns in relation to the daily administration of the ESAS in a specialist palliative care unit.

\section{Study Limitations}

To date there have been comparatively few studies in the area of the implementation process of symptom assessment tools in a tertiary palliative care unit. The questionnaire survey population was a convenience sample and the small number present in the focus group $(\mathrm{n}=8)$ are limitations and may have limited generalisability.

\section{Conclusions}

Managing patient's debilitating symptoms is an integral part of palliative care. These symptoms require evaluation in a manner that is systematic. However, this should be done in a manner that is not unduly burdensome to patients or staff [10].

The completion of the above study highlights the challenges of implementing symptom assessment tools at ward level in a specialist palliative care unit. Areas that warrant further research are the development of a shorter symptom assessment tool that encompass the patients 24 -hour symptom profile, and that can be filled out by the nurse caring for the patient retrospectively once a day. This could reduce the patient and staff burden and also allow nursing staff to make the daily symptom score more representative of the patient's true profile. However, the ESAS is primarily a patient scored tool and has been validated as such, and the issue of the accuracy of proxy ratings needs to be incorporated into this research. The development of a nurse scored tool would need further development and validation. As part of managing symptoms correctly and comprehensively in a specialist palliative care unit the use of symptom assessment tools as outcome measures of patient comfort are used in many centers. The above study highlights some of the challenges of implementing these tools at ward level.

Since the completion of this study, Milford Hospice has undertaken a major review of all patient assessment documents including the use of other symptom assessment scales and quality of life tools.

\section{References}

1. Cleeland CS, Mendoza TR, Wang XS, Chou C, Harle MT, et al. (2000) Assessing symptom distress in cancer patients: the M.D. Anderson Symptom Inventory. Cancer 89: 1634-1646.

2. Portenoy RK, Thaler HT, Kornblith AB, Lepore JM, Friedlander-Klar H, et al. (1994) Symptom prevalence, characteristics and distress in a cancer population. Qual Life Res 3: 183-189.

3. Kirkova J, Davis MP, Walsh D, Tiernan E, O'Leary N, et al. (2006) Cancer Symptom Assessment Instruments: A Systematic Review. J Clin Onc 24: 1459-1473.

4. Philip J, Smith W.B., Craft P, Lickiss N (1998) Concurrent validity of the modified Edmonton Symptom Assessment System with the Rotterdam Symptom Checklist and the Brief Pain Inventory. Supportive Cancer Care 6: 539-541.

5. Strömgren AS, Groenvold M, Pedersen L, Olsen AK, Sjogren P (2002) Symptomatology of cancer patients in palliative care: content validation of selfassessment questionnaires against medical records. Eur J Cancer 38:788-794.

6. Graneheim UH, Lundman B (2004) Qualitative content analysis in nursing research: concepts, procedures and measures to achieve trustworthiness. Nurse Education Today 24: 105-112.

7. Burnard $P$ (1991) A method of analysing interview transcripts in qualitative research. Nurse Educ Today 11: 461-466.

8. Morse JM, Field PA (1985) Nursing research: the application of qualitative approaches. (2ndedn) Stanley Thomes Ltd. United Kingdom.

9. Rees E, Hardy J, Ling J, Broadley K, A'Hern R (1998) The use of the Edmonton Symptom Assessment Scale (ESAS) within a palliative care unit in the UK. Palliat Med 12: 75-82.

10. Watanabe S, McKinnon S, Macmillan K, Hanson J (2006) Palliative care nurses' perceptions of the Edmonton Symptom Assessment Scale: a pilot survey. Int J Palliat Nurs 12: 111-114.

11. Szerlip N, Rutter C, Ram N, Yovino S, Kwok Y, et al. (2011) Factors impacting volumetric white matter changes following whole brain radiation therapy. J Neurooncol 103: 111-119. 
Citation: Lucey M, Conroy M, Ryan K (2012) Exploring the Challenges of Implementing the Edmonton Symptom Assessment Scale in a Specialist Palliative Care Unit. J Palliative Care Med 2:128. doi:10.4172/2165-7386.1000128

12. Labori KJ, Hjermstad MJ, Wester T, Buanes T, Loge JH (2006) Symptom profiles and palliative care in advanced pancreatic cancer: a prospective study. Support Care Cancer 14: 1126-1133.

13. Bruera E, MacDonald S (1993) Audit methods: The Edmonton Symptom Assessment System. In: Higginson I, editor. Clinical Audit in Palliative Care. Oxford: Radcliffe Medical Press.

14. Tierney RM, Horton SM, Hannan TJ, Tierney WM (1998) Relationships between symptom relief, quality of life, and satisfaction with hospice care. Palliat Med 12: 333-344.

15. Chow E, Wong R, Connolly R, Hruby G, Franzcr, et al. (2001) Prospective assessment of symptom palliation for patients attending a rapid response radiotherapy program. feasibility of telephone follow-up. J Pain Symptom Manage 22: 649-656.

16. Lindemalm C, Strang $P$, Lekander M (2003) Support group for cancer patients. Does it improve their physical and psychological wellbeing? A pilot Study. Support Care Cancer 13: 652-657.

17. Nekolaichuk CL, Bruera E, Spachynski K, MacEachern T, Hanson J, et al (1999) A comparison of patient and proxy symptom assessments in advanced cancer patients. Palliat Med 13: 311-323.

18. Nekolaichuk CL, Maguire TO, Suarez-Almazor M, Rogers WT, Bruera E (1999) Assessing the reliability of patient, nurse, and family caregiver symptom ratings in hospitalized advanced cancer patients. J Clin oncol 17: 3621-3630.
19. Pautex S, Berger A, Chatelain C, Herrmann F, Zulian GB (2003 Symptom assessment in elderly cancer patients receiving palliative care. Crit Rev Onco Hematol 47: 281-286.

20. Caraceni A, Cherny N, Fainsinger R, Kaasa S, Poulain P, et al. (2002) Pain measurement tools and methods in clinical research in palliative care: recommendations of an Expert Working Group of the European Association of Palliative Care. J Pain Symptom Manage 23: 239-255.

21. Shannon MM, Ryan MA, D'Agostino N, Brescia FJ (1995) Assessment of pain in advanced cancer patients. J Pain Symptom Manage 10: 274-278.

22. Campbell WI (2003) Practical methods for pain intensity measurements. In Breivik H, Campbell WI, Eccleston C, eds. Practical applications \& procedures (1st edn) London, United Kingdom.

23. Twycross R, Harcourt J, Bergl S (1996) A survey of pain in patients with advanced cancer. J Pain Symptom Manage 12: 273-282.

24. Radbruch L, Sabatowski R, Loick G, Jonen-Thielemann I, Kasper M, et al. (2000) Cognitive impairment and its influence on pain and symptom assessment in a palliative care unit: development of a Minimal Documentation System. Palliat Med 14: 266-276.

25. Klepstad P, Loge JH, Borchgrevink PC, Mendoza TR, Cleeland CS, et al. (2002) The Norwegian brief pain inventory questionnaire: translation and validation in cancer pain patients. J Pain Symptom Manage 24: 517-525.
Submit your next manuscript and get advantages of OMICS Group submissions

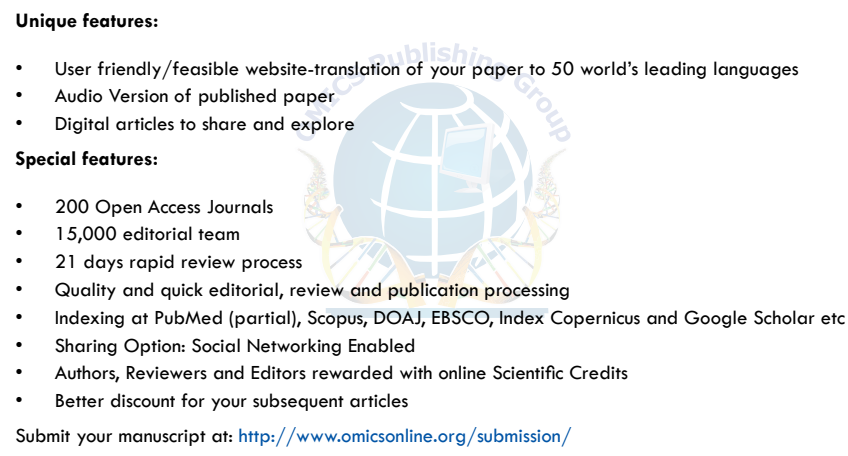

